\title{
ASSESSMENT OF PUBLIC AWARENESS IN THE FIELD OF EPIDEMIOLOGY, PREVENTION AND TREATMENT OF CHRONIC VENOUS DISEASES IN POLAND
}

Tomasz Urbanek', Andrzej Dorobisz², Marcin Gabriel3', Włodzimierz Hendiger', Arkadiusz Jawieńn, Marcin Kucharzewski ${ }^{6}$, Grzegorz Madycki ${ }^{7}$, Zbigniew Rybak', Walerian Staszkiewicz', Tomasz Zubilewicz' ${ }^{10}$, Krzysztof Ziaja'

'Department of General and Vascular Surgery, Medical University of Silesia, Katowice, Poland 2Department of Vascular Surgery, General Surgery and Transplantology, Medical University, Wroclaw, Poland

${ }^{3}$ Department of General and Vascular Surgery, University of Medical Sciences, Poznan, Poland ${ }^{4}$ Department of Vascular Surgery and Angiology of the Medical Centre of Postgraduate Studies, Warsaw, Poland

${ }^{5}$ Department of Vascular Surgery and Angiology, Nicolaus Copernicus University Collegium Medicum in Bydgoszcz, Poland

${ }^{6}$ Department of General Surgery, Vascular Surgery and Angiology, Clinical Hospital no. 7, Katowice, Poland

${ }^{7}$ Department of Vascular Surgery and Angiology of the Medical Centre of Postgraduate Studies, Warsaw, Poland

${ }^{8}$ Department of Experimental Surgery and Biomaterials, Medical University, Wroclaw, Poland ${ }^{9}$ Department of Vascular Surgery and Angiology of the Medical Centre of Postgraduate Studies, Warsaw, Poland

${ }^{10}$ Department of Vascular Surgery and Angiology, Medical University of Lublin, Poland
ORIGINAL PAPER

Phlebological Review 2015; 23, 2: 45-53 DOl: $10.5114 /$ pr.2015.54035

Submitted: 28.07 .2015

Accepted: 26.08 .2015

\begin{abstract}
Aim of the study: Both prevention and treatment of chronic venous disease (CVD) are potentially related to the proper patient knowledge in this field. This paper presents the results of a study commissioned by Polish Society of Phlebology concerning the patient awareness in the field of epidemiology, prevention and treatment of CVD in Poland.

Material and methods: The study was performed with the use of computer-assisted interviews conducted on a nationwide representative sample $(n=828)$ and additionally on a nationwide representative sample of women $(n=177)$.

Results: The most common complaint reported by the respondents was a feeling of heaviness and fatigue in the lower limbs $-62 \%$. Thirty-seven percent reported lowerleg pain related to body posture and 33\% lower limb swelling. In $27 \%$ the presence of varicose veins and in $2 \%$ crural ulcers were reported. The majority of symptomatic respondents (64\%) never reported their problems to the physicians; $23 \%$ of them received assistance from a pharmacist. Among symptomatic patients, compression therapy was used by $11 \%, 23 \%$ took medication, and $18 \%$ received dietary supplements. The most common source of information on CVD was the knowledge obtained from friends and families (37\%) and from the media (37\%). Only $22 \%$ indicated the physician as a knowledge resource. As many as 7 out of 10 respondents believed that the education in the area of CVD is necessary.

Conclusions: Despite the fact that CVD are widespread among patients, they are still rarely diagnosed by medical personnel and the level of patient knowledge concerning CVD remains low.
\end{abstract}

Key words: chronic venous disease, epidemiology, prevention, treatment.

\section{ADDRESS FOR CORRESPONDENCE}

Tomasz Urbanek

Department of General and Vascular Surgery Medical University of Silesia

Ziołowa 45/47, 40-635 Katowice

e-mail: urbanek.tom@interia.pl 


\section{INTRODUCTION}

Chronic venous diseases (CVD) of the lower limbs belong to the most common diseases of the vascular system. Epidemiological studies related to CVD suggest that they affects $2-56 \%$ of men and $1-73 \%$ of women; the incidence in the population significantly increases with age [1-4]. Significant differences related to the extremely diverse reported incidence of CVD result from the differences between study populations and from the evaluation methods adopted by authors of these publications [1, 5-7]. According to the study by Jawien et al., among those patients who visited primary health care specialists, regardless of the reason for their appointment, $48 \%$ of adult Polish women and $37 \%$ of adult Polish men suffer from CVD. Varicose veins of the lower limbs, as the most common manifestation of the disease, were diagnosed in $48 \%$ of the patients who were diagnosed with CVD; oedema was reported in $11 \%$ of the patients [8]. In the entire study population, the presence of varicose veins was observed in $35.3 \%$ of women and $27.9 \%$ of men [8].

The prevalence of CVD also involves a significant risk of complications, even life-threatening ones, such as: superficial vein thrombosis and/or deep vein thrombosis. Their clinical symptoms have a significant impact on the quality of life (oedema, trophic lesions, and venous ulcers of the shin, a subjective feeling of heaviness, tiredness or pain in the area of the lower leg) [3, 9-13]. Despite the seemingly broadened knowledge shared by medical communities related to CVD, patient education in this regard still proves insufficient. It is primarily revealed by a large number of patients presenting an advanced stage of the disease (C4-C6). Insufficient public awareness makes the problem of venous system diseases a rare reason for medical consultations; on the other hand, patients often underestimate problems associated with their limbs.

This paper presents the results of a nationwide study of public awareness and the knowledge of adult Polish citizens concerning epidemiology, symptomatology and methods of prevention and treatment related to CVD. The study was conducted on the basis of the results of computer-assisted telephone interviews; it was carried out with the help of an independent agency specialised in public opinion research. The study was commissioned by Polish Society of Phlebology and supported by the research scientific grant of HASCO-LEK company.

\section{MATERIAL AND METHODS}

The study was performed in the period between 31 March and 11 April 2014; it was conducted all over Poland on a nationwide representative sample of respondents of both sexes. The study was commissioned by the Polish Society of Phlebology and completed by IMAS
International Sp. z o.o., Instytut Badania Rynku i Opinii Społecznej (Institute for Market Research and Public Opinion). The study included 20-80 year-old respondents from all Polish provinces; the study was performed on the basis of computer-assisted telephone interviews; the study was based on a questionnaire developed by the Contractor together with the Polish Society of Phlebology. The study population included the main sample representative of the Polish population aged 20-80 $(n=828)$ and an additional sample of women representative of the population of women aged $20-80(n=177)$. The study was performed based on randomly selected telephone numbers and randomly selected cell phone numbers. Distribution of the study population by sex, age, province and class of the place of residence, and after weighting data about educational level reflected the distribution of a general Polish population aged 20-80: $22 \%$ of respondents were aged $20-30 ; 28 \%$ were aged $31-45 ; 28 \%$ were aged 46-60; and 22\% were aged 61-80. Thirty-nine percent of respondents lived in rural areas; $23 \%$ of them lived in cities of fewer than 50,000 inhabitants; $16 \%$ of the respondents lived in cities of 51,000-200,000 inhabitants, $16 \%$ of them lived in cities of more than 200,000 inhabitants and 5\% of them lived in Warsaw. Forty-two percent of the respondents confirmed having basic primary education or basic vocational training; $36 \%$ of them completed secondary school education and $22 \%$ of them graduated from higher education institutions. The aim of this study was to determine the prevalence of potential risk factors for CVD (related to lifestyle, the nature of work, physical activity or the lack of it, stimulants and patient's family burden) and to identify the symptoms and signs of CVD declared by the Polish study subjects. The study also involved questions about the ways to treat ailments of the lower limbs and the frequency with which the respondents used medical and pharmaceutical assistance for those reasons. The survey also included questions aimed at determining the level of the subjects' knowledge about the causes of varicose veins and swelling and the possible complications of CVD. The study identified the sources of information on varicose veins used by the respondents; other questions were also related to the respondents' sense of being well-informed about the treatment and prevention of vein diseases, and the definition of their expectations concerning the related information published in the media. The results were evaluated as a whole and also as divided by sex. A detailed analysis also included the respondents' age.

In the study population, $56 \%$ of individuals were employed and $44 \%$ were unemployed. Among the unemployed, $12 \%$ were students, $66 \%$ lived of pension or allowance or remained on a long-term leave; $22 \%$ were unemployed and searching for work. Among the employed respondents, $57 \%$ considered their work to be physical; $43 \%$ declared to be white-collar workers and $35 \%$ of the working group said their work mostly required a sitting 
Feeling of heaviness and fatigue in the lower limbs after a longer period of standing or sitting

Cramps within the lower limbs after a longer period of standing or sitting
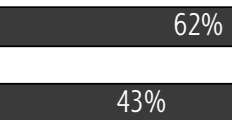

Lower leg pain after a longer period of standing or sitting

Spider veins within the lower legs

$36 \%$

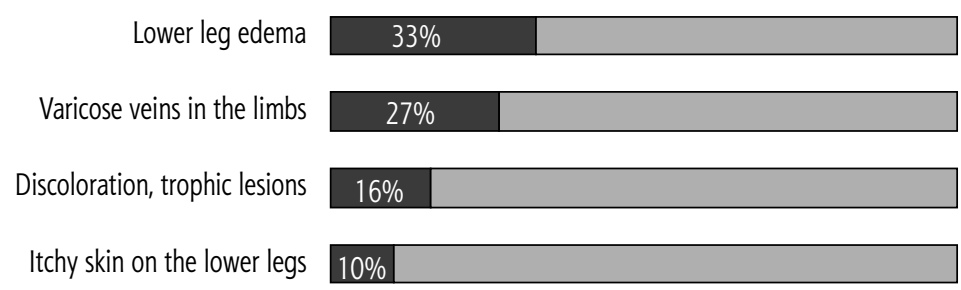

Skin ulcerations

Fig. 1. The frequency of signs and symptoms potentially associated with chronic venous disease in the study population

position, $17 \%$ maintained it required a standing position, and $48 \%$ said their work required walking; $38 \%$ of the respondents maintained that they would spend less than 4 hours a day in a seated position; $37 \%$ said that they would remain seated 4 and 8 hours a day; $23 \%$ reported that they spend at least 8 hours a day in a sitting position. Twenty-four percent of the respondents reported that they would spend less than 4 hours daily in a standing position; $32 \%$ of the respondents rated that they would spend between 4 and 8 hours a day seated, and $42 \%$ declared that they would spend at least 8 hours a day in a standing position.

\section{RESULTS}

\section{Characteristics of the symptoms reported by the study group}

Fifty-six percent of the respondents reported that their close family members (parents, grandparents or siblings) had varicose veins; $79 \%$ of the respondents who suffered from varicose veins had a close relative affected by the problem (in the group of patients without varicose veins, less than half of it, i.e. $48 \%$, declared that their parents, grandparents or siblings were diagnosed with varicose veins). When asked about the ailments potentially associated with CVD, the respondents first mentioned a feeling of heaviness and fatigue of the lower limbs after a long period of standing or sitting, which problems occurred in $62 \%$ of the subjects. Lower-leg pain and swelling related to $36 \%$ and $35 \%$ of the respondents, respectively; varicose veins were reported by $27 \%$ of the respondents. Other symptoms potentially associated with CVD are listed in the diagram in Fig. 1. In more than half of the respondents under 30 years of age (55\%), varicose veins remained for no longer than 5 years. In each subsequent age group, more and more respondents reported that the period from the onset of varicose veins was longer. Among the oldest respondents (age range: $61-80$ ), 45\% reported the presence of varicose veins for over 20 years; in $22 \%$ they were present for $10-20$ years; $18 \%$ reported the presence of varicose veins for 5-10 years and $8 \%$ had them for less than 5 years.

The ailments reported by the respondents differed significantly depending on gender and age. The symptoms potentially associated with CVD were more often reported by women (Table 1). According to the respondents' declarations, varicose veins were almost twice more common in women than men. In relation to spider veins (telangiectasia), the trend was even more pronounced: they were thrice more common in women than in men. The incidence of particular problems related to the lower limbs increases with age. That trend is particularly evident in the case of varicose veins; in people aged 61-80 varicose veins are more than 5 times more frequent than in the youngest age group (20-30 years old); other ailments occur about 2 to 3.5 times more frequently in the oldest study group (61-80 years of age) than in those at the age of $20-29$. Only $20 \%$ of the respondents (28\% of men and $13 \%$ of women) did not report any complaints mentioned in the survey.

Among the respondents with varicose veins, the majority also reported the presence of the following symptoms: $79 \%$ of the respondents reported a feeling of heaviness and fatigue within the lower limbs; $57 \%$ reported pain; and $52 \%$ reported swelling after a prolonged period of standing or sitting. At the same time, skin hyperpigmentation around the ankle and lower leg was reported by $40 \%$ of the respondents with varicose veins and the occurrence of chronic non-healing wounds on the shin (ulcers) were reported by $4 \%$ of the respondents with varicose veins. 
Table 1. Symptoms and signs in the lower limbs according to age and sex of the respondents

\begin{tabular}{|c|c|c|c|c|c|c|}
\hline $\begin{array}{l}\text { Symptoms and signs } \\
\text { related to the lower limbs }\end{array}$ & $\begin{array}{c}\text { Men } \\
(n=401) \\
\%\end{array}$ & $\begin{array}{c}\text { Women } \\
(n=604) \\
\%\end{array}$ & $\begin{array}{c}20-30 \text { years } \\
(n=185) \\
\%\end{array}$ & $\begin{array}{c}31-45 \text { years } \\
(n=236) \\
\%\end{array}$ & $\begin{array}{c}46-60 \text { years } \\
(n=228) \\
\%\end{array}$ & $\begin{array}{c}61-80 \text { years } \\
(n=179) \\
\%\end{array}$ \\
\hline $\begin{array}{l}\text { A feeling of heaviness and fatigue of the lower leg after } \\
\text { standing or sitting }\end{array}$ & 54 & 70 & 55 & 57 & 69 & 66 \\
\hline $\begin{array}{l}\text { Cramps in the lower leg after a long period of standing } \\
\text { or sitting }\end{array}$ & 39 & 46 & 30 & 38 & 49 & 54 \\
\hline $\begin{array}{l}\text { Pains in the lower leg after a longer period of standing } \\
\text { or sitting }\end{array}$ & 36 & 37 & 25 & 32 & 46 & 46 \\
\hline Spider veins & 17 & 51 & 19 & 37 & 39 & 47 \\
\hline Oedema of the lower limbs & 24 & 40 & 17 & 31 & 35 & 48 \\
\hline Varicose veins of the lower limbs & 19 & 32 & 8 & 23 & 32 & 44 \\
\hline Trophic discolorations on the lower leg or ankle area & 13 & 18 & 8 & 13 & 20 & 23 \\
\hline Itching of the skin around the lower leg & 8 & 12 & 5 & 7 & 11 & 18 \\
\hline Shin ulceration & 1 & 1 & 1 & 1 & 1 & 4 \\
\hline
\end{tabular}

\section{Therapeutic management in symptomatic patients}

The respondents who reported the above-mentioned problems in the lower limbs were also asked to identify the methods used by them on a daily basis in order to reduce the discomfort associated with the presence of these symptoms. The most common method was to elevate the lower limbs as often as possible (57\%). The second most commonly mentioned method of treatment was the use of topical drugs for limbs, that is gels, ointments, creams or sprays (39\%); $17 \%$ of the respondents used cold compresses to relieve the ailments. Pharmacological, orally administered treatment was used only by a part of the symptomatic group of respondents: $23 \%$ of them used phlebotropic medication and $18 \%$ used dietary supplements. Only $11 \%$ of the respondents with symptoms in the lower limbs mentioned the use of compression treatment with bandages or commercially available compression products (graduated compression stockings). Four percent of the respondents reported that they underwent a previous varicose vein surgery. It is interesting that only $36 \%$ of the respondents who confirmed the existence of the above symptoms potentially associated with CVD completed an appointment with a doctor; $23 \%$ of them received assistance from a pharmacist, and as many as $28 \%$ never used any method of treatment, neither in the form of medical recommendations, nor self-medication. Table 2 shows the use of pharmaceutical therapy, nutritional supplements and topical methods of treatment depending on gender and age. The analysis of the method of treatment also included the incidence of varicose veins. As it becomes clear from the survey, women much more often than men attempt to treat their aliments (the percentage of those who take up treatment in the group of symptomatic respondents: women $-80 \%$, men $-61 \%)$. As much as half of the youngest group of respondents (51\%, aged 20-30) with reported problems within the lower limbs did not take up any treatment. These figures decreased with age progression and in the age interval between 61 and 80 years concerned only $18 \%$ of such patients. Patients with varicose veins were much more likely to use various forms of treatment - only $16 \%$ of them were never treated due to varicose veins or related symptoms.

The percentage of respondents seeking medical help (in the group of symptomatic subjects) significantly differs with age. In the age group of $20-30,9 \%$ of the respondents who had problems reported them to a doctor; in the age group of $31-4529 \%$ of the subjects visited a doctor; in the age group of 46-60 $42 \%$ of them visited a doctor; in the age group of $61-8056 \%$ of them had a doctor's appointment. Among the respondents with varicose veins, $53 \%$ consulted a doctor due to their problems. Among the respondents with other problems than varicose veins, only $27 \%$ reported a prior medical consultation in relation to the problems associated with those ailments.

\section{Patient knowledge in terms of risk factors and chronic complications of venous diseases of the lower limbs}

Fifty-nine percent of the respondents considered the nature of their work and lifestyle as an important cause of venous insufficiency. Fewer respondents (36\%) considered genetic factors to be the cause of CVD. Every fourth respondent concluded that genetic factors are of minor or no importance, while in the case of the above-mentioned environmental factors only $11 \%$ of the respondents 
Table 2. The use of pharmacological therapies (topical and oral drugs, dietary supplements and compression therapy) by symptomatic patients according to gender, age and the presence of varicose veins

\begin{tabular}{|c|c|c|c|c|c|c|c|c|}
\hline $\begin{array}{l}\text { Management methods in the group } \\
\text { of symptomatic patients }\end{array}$ & $\begin{array}{c}\text { Men } \\
(n=276) \\
\%\end{array}$ & $\begin{array}{c}\text { Women } \\
(n=523) \\
\%\end{array}$ & $\begin{array}{c}20-30 \\
\text { years } \\
(n=127) \\
\%\end{array}$ & $\begin{array}{c}31-45 \\
\text { years } \\
(n=179) \\
\%\end{array}$ & $\begin{array}{c}46-60 \\
\text { years } \\
(n=191) \\
\%\end{array}$ & $\begin{array}{c}61-80 \\
\text { years } \\
(n=155) \\
\%\end{array}$ & $\begin{array}{l}\text { Patients without } \\
\text { varicose veins } \\
(n=440) \\
\%\end{array}$ & $\begin{array}{c}\text { Patients with } \\
\text { varicose veins } \\
(n=212) \\
\%\end{array}$ \\
\hline The use of pharmacological medication & 19 & 25 & 2 & 17 & 28 & 41 & 15 & 38 \\
\hline The use of dietary supplements & 13 & 22 & 12 & 14 & 20 & 23 & 15 & 23 \\
\hline Ointments, gels, creams, sprays & 28 & 43 & 23 & 30 & 47 & 51 & 30 & 56 \\
\hline The application of cool compresses & 15 & 18 & 8 & 16 & 21 & 21 & 15 & 23 \\
\hline $\begin{array}{l}\text { The use of compression therapy: } \\
\text { compression stockings, bandages }\end{array}$ & 10 & 15 & 2 & 7 & 14 & 19 & 4 & 25 \\
\hline Elevation of the lower limbs & 40 & 68 & 36 & 59 & 64 & 63 & 49 & 73 \\
\hline $\begin{array}{l}\text { Past surgical treatment - surgery due } \\
\text { to varicose veins of the limbs }\end{array}$ & 3 & 5 & 0 & 3 & 7 & 7 & 0,2 & 13 \\
\hline $\begin{array}{l}\text { Other invasive procedures for varicose } \\
\text { veins or spider veins }\end{array}$ & 1 & 3 & 0 & 3 & 4 & 2 & 1 & 5 \\
\hline Other methods of treatment & 4 & 7 & 2 & 8 & 5 & 7 & 5 & 6 \\
\hline No previous or current treatment & 39 & 20 & 51 & 28 & 22 & 18 & 34 & 16 \\
\hline
\end{tabular}

thought these were of minor or no importance. According to the vast majority of respondents $(81 \%)$, varicose veins are more of a health than an aesthetic problem; $14 \%$ of the respondents expressed the opposite view, and every twentieth respondent could not answer such questions. When asked how often varicose veins occur, $18 \%$ of the respondents replied that they affect up to $20 \%$ of the adult population, $29 \%$ estimated the percentage of patients with varicose veins at the level of $21-40 \%, 21 \%$ of the respondents estimated it at the level of $41-60 \%$, and $8 \%$ of the respondents estimated it at a level above $60 \%$ of the population. The following risk factors which exacerbate the problems associated with CVD (including varicose veins and swelling) were identified by the respondents; $93 \%$ of them pointed to being overweight or obese, $87 \%$ pointed to long periods of standing or sitting, $80 \%$ pointed to no physical activity, $77 \%$ pointed to pregnancy, $56 \%$ pointed to heat/hot weather and $38 \%$ pointed to hormonal treatment. At the same time, as many as $73 \%$ of the respondents considered arterial hypertension to be a risk factor affecting the progress of the disease, $60 \%$ of them mentioned smoking, 53\% - alcohol consumption, $24 \%$ - intensive running, and $17 \%$ - cycling. Women and respondents with higher education less often pointed to running and cycling as a risk factor; more often they would mention nearly all other factors, especially hormonal medication and high temperature.

When asked about the complications, ailments and problems that are the potential consequences of varicose veins, the respondents most frequently mentioned problems within the vascular system such as blood clots and embolisms (30\% of respondents), "circulatory disorder in the limbs" $(25 \%)$, problems with walking and mobility (15\%), pain in the lower extremities (15\%), haemorrhage, stroke, heart attack, bleeding (12\%), heart problems, heart diseases $(6 \%)$, aesthetic problems, discolorations (6\%), limb amputations (3\%) and death (2\%). However, $24 \%$ of the respondents were unable to spontaneously mention any health consequences that would be potentially connected with the presence of varicose veins.

During telephone interviews the respondents were also inquired about the widely-known and most common complications of varicose veins. A positive response to the question whether varicose veins can lead to deep vein thrombosis was given by $86 \%$ of the respondents, $76 \%$ of them confirmed possible skin discolorations and $58 \%$ - venous ulcerations of the shin. The respondents were asked to provide up to three media sources that they use every day; they usually mentioned television (74\%), a significant proportion of them $(57 \%)$ pointed to the internet, $43 \%$ pointed to the radio, every fourth respondent mentioned daily newspapers and every fifth one mentioned magazines. With regard to the sources of the respondents' knowledge about varicose veins, only $22 \%$ reported that it was derived from doctors; $9 \%$ said that pharmacists played the role of a knowledge resource. Much more often than from the medical personnel, the respondents obtained information on varicose veins from their families $(37 \%)$ or friends (35\%) or from the television (37\%), internet (32\%), magazines (29\%), newspapers (16\%), advertisements/commercials (28\%) or the radio (17\%); $16 \%$ admitted that they had no interest in the problem of varicose veins. 
As general practitioners (GPs) are more available than specialists, it seems that they should play an important role in informing the patients about the disease and the prevention options. A significant portion of the respondents (84\%) believed that general practitioners should pay more attention to varicose veins and related ailments; almost every tenth respondent expressed the opposite view, and an equal number of respondents had no opinion. It seems very important that - as claimed by the respondents - in $65 \%$ of cases general practitioners never asked them about varicose veins, pain or swelling of the lower limbs (Fig. 2).

Answers to this question vary considerably; however, they depend on the age of the respondents. Older peo-

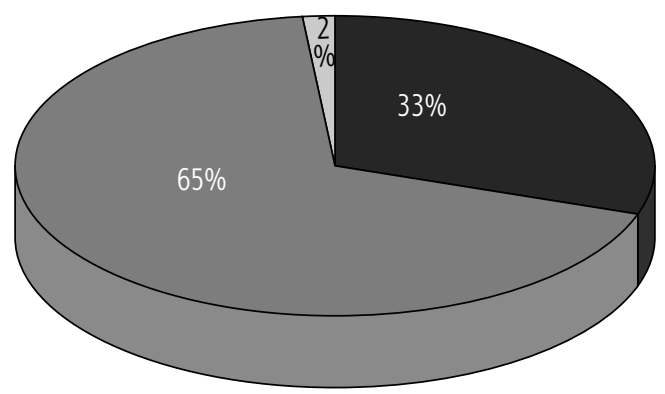

$$
\begin{aligned}
& \square \text { Yes } \\
& \square \text { No } \\
& \square \text { Hard to say }
\end{aligned}
$$

Fig. 2. The results of the respondents' answers to the question: "Has your general practitioner ever asked you about the condition of your lower limbs?" ple more often admitted that their general practitioners asked them about the symptoms of venous insufficiency - a clear difference in this respect is evident in the group of respondents over 45 years of age (Table 3 ).

When asked about the specialization of the physicians dealing with venous diseases, the respondents most often (in as many as $54 \%$ of cases) could not answer that question: $27 \%$ of them mentioned vascular surgeons; $8 \%$ mentioned cardiologists; other answers did not exceed $3 \%$. Phlebologists and angiologists were only mentioned by 1 and $2 \%$, respectively.

A subjective impression related to being aware of the methods of prevention and treatment of venous diseases of the lower limbs was high. Every fourth respondent believed that he or she is not informed at all, neither in relation to the prevention, nor treatment of these ailments. Those individuals, including the respondents who think they are poorly informed, account for nearly half of all the respondents (Fig. 3).

As many as $70 \%$ of the respondents believed that the problem of venous diseases should be more publicised in the media, and as many as $54 \%$ were positive about it. The opposite view was expressed by every tenth respondent, and an ambivalent attitude towards the issue was declared by $17 \%$ of the respondents.

\section{DISCUSSION}

Although CVD rarely lead to life-threatening complications for the patient, their high prevalence and diverse symptomatology make an important health problem and at the same time generate significant social costs $[2,5,9$,

$$
\begin{aligned}
& \text { How well informed are you in terms of what to do and how to react when such } \\
& \text { ailments occur? } \\
& 26 \% \\
& 19 \% \\
& 23 \% \\
& 13 \% \quad 16 \%
\end{aligned}
$$

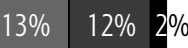

\begin{tabular}{|c|c|}
\hline $27 \%$ \\
\hline
\end{tabular}

$22 \%$

$24 \%$

Fig. 3. Subjective impression related to being aware of the methods of prevention and treatment of venous diseases of the lower limbs

Table 3. Answers the question about general practitioner's interest in the condition of the patient's lower limbs depending on age and sex of the respondents ("Has your general practitioner ever asked you about the condition of your lower limbs?")

\begin{tabular}{lcccccc}
\hline & $\begin{array}{c}\text { Men } \\
(n=401) \\
\%\end{array}$ & $\begin{array}{c}\text { Women } \\
(n=604) \\
\%\end{array}$ & $\begin{array}{c}20-30 \text { years } \\
(\boldsymbol{n}=185) \\
\%\end{array}$ & $\begin{array}{c}31-45 \text { years } \\
(\boldsymbol{n}=236) \\
\%\end{array}$ & $\begin{array}{c}46-60 \text { years } \\
(\boldsymbol{n}=228) \\
\%\end{array}$ & $\begin{array}{c}61-80 \text { years } \\
(\boldsymbol{n}=179) \\
\%\end{array}$ \\
\hline Yes & 29 & 34 & 10 & 19 & 45 & 60 \\
\hline No & 68 & 65 & 89 & 78 & 54 & 39 \\
\hline It is hard to say/ & 3 & 1 & 1 & 3 & 1 & 1 \\
I do not remember & & & & & & \\
\hline
\end{tabular}


14]. Local complications of the disease (including venous ulcer) and the potential impact of signs and symptoms of CVD on the patient's quality of life often limit the possibility of employment; treatment of these diseases represents a significant financial burden for the health care system and the patient $[9,14-18]$.

In this regard, public awareness of the risk factors, potential complications of $\mathrm{CVD}$ and the treatment options/methods is of great importance, especially as it relates to a disease affecting so many patients. In Western countries, varicose veins of the lower limbs occur in $25-33 \%$ of women and $10-40 \%$ of men; venous shin ulcerations (healed or active) affect $1 \%$ of the adult population $[1,9]$. In the studies conducted in France, Germany and Poland, the percentage of patients with diagnosed oedema associated with venous insufficiency ranged from $1 \%$ to $14.9 \%$, and trophic lesions of the skin in the lower-leg areas were observed in $2.1-13.2 \%$ [8, 19, 20]. This data is not entirely consistent with other reports which suggest a significantly higher incidence of CVD. A study completed in 2014 in Saudi Arabia suggests that the incidence of CVD is at the level of $61.6 \%$ (women: 69\%, men: 45\%) [4]. A study by Vuylstke et al., based on the assessment of CVD symptoms by 406 GPs in Belgium and Luxembourg (a total of 6009 study patients reporting to GPs), suggests the occurrence of CVD symptoms, especially the feeling of heaviness, pain and oedema in $61.3 \%$ of respondents [5]. An interesting observation was made: due to the reported complaints, up to $10.4 \%$ of patients required a certificate of being at least temporarily unfit for work [5]. In another study among the residents of Edinburgh (Scotland) the presence of telangiectasia and reticular veins was found in $80 \%$ of men and $85 \%$ of women aged 18-64; swollen extremities were reported in $7 \%$ of men and $16 \%$ of women [21]. Escudero Rodrigues et al., in a study on the population 19,800 patients at a mean age of $53.7 \pm 20$, diagnosed CVD in $48.5 \%$ of the subjects, with a significantly higher incidence of CVD in women $(58.5 \%)$ than men $(32.1 \%)$ [22].

Certainly the definition of CVD adopted in the study, the methodology used and the study population (e.g. the general population, patients reporting to physicians due to other problems not necessarily associated with CVD) are all of great importance for the way in which individual studies can be interpreted [23-26].

In this study, over $70 \%$ of respondents reported the presence of CVD symptoms. Only $28 \%$ of male respondents and $13 \%$ of women reported no ailments in the lower limbs. Although it should be assumed that not all the symptoms reported may be of venous origin (e.g. swelling), as the study was carried out in the form of interviews, as many as $27 \%$ of the respondents reported varicose veins which are usually easy to diagnose. It is important that the incidence of varicose veins in this survey corresponds to the incidence of varicose veins found earlier in other studies conducted in Poland $[8,9]$.
Despite the seemingly greater awareness of the problem of CVD, only $36 \%$ of the respondents visited a doctor due to that problem. Older patients more often used medical assistance (56\% of those aged $61-80$ ); the subjects with visible varicose veins (53\%) more often visited doctors, while those without visible varicose veins were much less likely to seek medical advice (27\%).

Patient education makes an important element in both the prevention and treatment of CVD [9, 27]. Early recognition of symptoms, change of one's lifestyle and promotion of those behaviours which can improve the activity of muscle pump are essential in the process of CVD treatment [9, 27-31]. Therefore, the teaching activities taken up by the medical personnel are insufficient in relation to CVD. Only $22 \%$ of the respondents received some information from their doctors on varicose veins of the lower limbs and potentially related problems; much more often the sources of the subjects' knowledge were: the television, the internet or friends. A significant portion of the patient group was not able to identify the specialization of a doctor they should relate to with problems indicating CVD.

While analysing the results the authors of this study were much aware of the limitations of the present study. The method of gathering information over the phone and no physical examination are certainly important factors affecting the assessment of the prevalence of the signs and symptoms potentially associated with venous system incompetence. Subjective assessment reported by the respondents and inability to use objective scales to assess the severity of damage to the venous system (e.g. VCSS - venous clinical severity score, CEAP) or the worsened quality of life associated with the disease (e.g. CIVIQ, VEINS-QUAL) resulted from the methodology adopted in the study $[9,23,27]$. However, it was for the first time in Poland that the level of knowledge about this very common condition, its risk factors, complications, and treatment options could be assessed along with the prevalence of signs and symptoms of CVD. The analysis helped us suggest some important conclusions not only for the Polish Society of Phlebology (who commissioned the study) but also for the entire health care system. Considering the huge costs associated with the treatment of various forms of CVD (including the most severe cases of venous ulcerations), in light of the study results it seems reasonable and necessary to carry out extensive educational activities in this field. So far, there has been no extensive research conducted in Poland that would enable an actual assessment of the costs related to the occurrence and treatment of CVD. Estimated costs in Western European countries suggest that the annual cost of treating CVD amounts to 1-2\% of the budget of health care system and in the USA the estimated annual cost of treatment amounts to 3 billion dollars [9]. Indirect costs associated with the occurrence of CVD, sick leave or disability pension are also considerable - in the 
USA, venous ulceration of the shin results in 2 million working days of absence taken annually; in France an estimated annual number of days related to the patients' being unfit for work due to CVD and its complications is about 4 million [9]. Unfortunately, the data related to the total or estimated cost of treatment provided to patients with CVD in Poland or the social costs associated with the disease is still unknown. However, the number of patients diagnosed with venous ulcerative lesions of the shin remains alarmingly high in Poland. In the study population, fewer than $2 \%$ of the patients confirmed the presence of non-healing shin wounds or wounds which tend to be hard to treat. Considering the results of the analysis and the insufficient level of education in relation to CVD among the population, the authors of this study would strongly support any and all educational activities aimed at increasing the patients' knowledge.

\section{CONCLUSIONS}

Despite the high incidence of CVD, the problem still seems to be little known in Poland. Information and education activities should be wide-spread; that relates to the causes of CVD, its symptoms and potential complications, the treatment options and methods of prevention.

Study commissioned by Polish Society of Phlebology and financed from the scientific research grant from HASCOLEK.

\section{References}

1. Milic D. Prevelence and socioeconomic data in chronic venous disease: how usefull are they in planning appriopriate management. Medicographia 2011; 3: 253-258.

2. Robertsson E., Evans C., Fowkes F.G. Epidemiology of chronic venous disease. Phlebology 2008; 23: 103-111.

3. Eberhardt E., Raffeto J. Chronic venous insufficiency. Circulation 2005; 111: 2398-2409.

4. Al Shammeri O., AlHamdan N., Al-Hothaly B., Midhet F., Hussain M., Al-Mohaimeed A. Chronic Venous Insufficiency: prevalence and effect of compression stockings. Int J Health Sci (Qassim) 2014; 8: 231-236.

5. Vuylsteke M.E., Thomis S., Guillaume G., Modliszewski M.L., Weides N., Staelens I. Epidemiological study on chronic venous disease in Belgium and Luxembourg: prevalence, risk factors, and symptomatology. Eur J Vasc Endovasc Surg 2015; 49: 432439.

6. Maurins U., Hoffmann B.H., Lösch C., Jöckel K.-H., Rabe E., Pannier F. Distribution and prevalence of reflux in the superficial and deep venous system in the general population - results from the Bonn Vein Study, Germany. J Vasc Surg 2008; 48: 680687.

7. McLafferty R.B., Lohr J.M., Caprini J.A., Passman M.A., Padberg F.T., Rooke T.W., Bush R.L., Zakaria A.A., Flinn W.R., Eklof B.G., Dalsing M.C., Markwell S.J., Wakefield T.W. Results of the National Pilot Screening Program for Venous Disease by the American Venous Forum. J Vasc Surg 2007; 45: 142-148.
8. Jawien A., Grzela T., Ochwat A. Prevalence of chronic venous insufficiency (CVI) in men and women in Poland: multicenter cross-sectional study in 40095 patients. Phlebology 2003; 18: 110-122.

9. Management of chronic venous disorders of the lower limbs. Guidelines according to scientific evidence. International Angiology 2014; 33: 87-208.

10. Meissner M.H., Natiello C., Nicholls S.C. Performance characteristics of the venous clinical severity score. J Vasc Surg 2002; 36: 89-95.

11. Jawien A. The influence of environmental factors in chronic venous insufficiency. Angiology 2003; 53: 245-256.

12. Beebe-Dimmer J.L., Pfeifer J.R., Engle J.S., Schottenfeld D. The Epidemiology of Chronic Venous Insufficiency and Varicose Veins. Ann Epidemiol 2005; 15: 175-184.

13. Jantet G. Chronic venous insufficiency: worldwide results of the RELIEF study. Reflux assessment and quality of life improvement with micronized flavonoids. Angiology 2002; 53: 245-256.

14. Bradbury A., Evans C., Allan P., Lee A., Ruckley C.V., Fowkes F.G. What are the symptoms of varicose veins? Edinburgh vein study cross sectional population survey. Br Med J 1999; 318: 353-356.

15. Da Silva A., Navarro M.F., Batalheiro J. The importance of chronic venous insufficiency: various preliminary data on its medico-social consequences. Phlebologie 1992; 45: 439-443.

16. Lafuma A., Fagnani F., Peltier-Pujol F., Rauss A. Venous disease in France: an unrecognized public health problem. J Mal Vasc 1994; 19: 185-189.

17. Dinkel R. Venous disorders, a cost intensive disease. Phlebology 1997; 26: 164-168.

18. Guex J.J., Myon E., Didier L., Nguyen Le C., Taieb C. Chronic venous disease: health status of a population and care impact on this health status through quality of life questionnaires. Int Angiol 2005; 24: 258-264.

19. Carpentier P.H., Maricq H.R., Biro C., Poncot-Makinen C.O., Franco A. Prevalence, risk factors, and clinical patterns of chronic venous disorders of lower limbs: a population-based study in France. J Vasc Surg 2004; 40: 650-659.

20. Rabe E., Pannier-Fischer F., Bromen K., et al. Bonn Vein Study by the German Society of Phlebology. Epidemiological study to investigate the prevalence and severity of chronic venous disorders in the urban and rural residential populations. Phlebologie 2003; 32: 1-14.

21. Ruckley C.V., Evans C.J., Allan P.L., Lee A.J., Fowkes F.G. Chronic venous insufficiency: clinical and duplex correlations. The Edinburgh Vein Study of venous disorders in the general population. J Vasc Surg 2002; 36: 520-525.

22. Escudero Rodríguez J.R., Fernández Quesada F., Bellmunt Montoya $S$. Prevalence and clinical characteristics of chronic venous disease in patients seen in primary care in Spain: results of the international study Vein Consult Program. Cir Esp 2014; 92: 539-546.

23. Porter J.M., Moneta G.L. An International Consensus Committee on Chronic Venous Disease. Reporting standards in venous disease: an update. J Vasc Surg 1995; 21: 635-645.

24. Eklof B., Rutherford R.B., Bergan J.J., Carpentier P.H., Gloviczki P., Kistner R.L., Meissner M.H., Moneta G.L., Myers K., Padberg F.T., Perrin M., Ruckley C.V., Smith P.C., Wakefield T.W.; American Venous Forum International Ad Hoc Committee for Revision of the CEAP Classification. Revision of the CEAP clas- 
sification for chronic venous disorders: consensus statement. J Vasc Surg 2004; 40: 1248-1252.

25. Andreozzi G.M., Signorelli S., Di Pino L., Garozzo S., Cacciaguerra G., Leone A., Martini R. Varicose symptoms without varicose veins: the hypotonic phlebopathy, epidemiology and pathophysiology. Min Cardioang 2000; 48: 277-285.

26. Uhl J.F., Cornu-Thenard A., Carpentier P.H., Schadeck M., Parpex P., Chleir F. Reproducibility of the "C" classes of the CEAP classification. J Phlebology 2001; 1: 39-48.

27. Guex J.J., Myon E., Didier L., Nguyen Le C., Taieb C. Chronic venous disease: health status of a population and care impact on this health status through quality of life questionnaires. Int Angiol 2005; 24: 258-264.

28. Franks P.J., Wright D.D.I., Moffat C.J., Stirling J., Fletcher A.E., Bulpitt C.J., McCollum C. Prevalence of venous disease: a community study in West London. Eur J Surg 1992; 158: 143-147.

29. Laurikka J.O., Sisto T., Tarkka M.R., Auvinen O., Hakama M. Risk indictors for varicose veins in forty to sixty-year-olds in the Tampere Varicose Vein Study. World J Surg 2002; 26: 648-651.

30. Sisto T., Reunanen A., Laurikka J., Impivaara O., Heliövaara M., Knekt P., Aromaa A. Prevalence and risk factors of varicose veins in lower extremities. Mini-Finland Health Survey. Eur J Surg 1995; 161: 405-414

31. Bergan J.J., Schmid-Schonbein G.W., Smith P.D., Nicolaides A.N., Boisseau M.R., Eklof B. Chronic Venous Disease. N Engl J Med 2006; 355: 488-498. 